\title{
Gradient engineered light absorption layer for enhanced carrier separation efficiency in perovskite solar cells
}

\section{Gaozhu Wu}

Xiamen University

Qing Zhu

Xiamen University

Teng Zhang

Xiamen University

Ziqi Zou

Xiamen University

Weiping Wang

Xiamen University

\section{Yiyan Cao}

Xiamen University

\section{Lijing Kong}

Xiamen University

Xuanli Zheng

Xiamen Huaxia University

Yaping Wu

Xiamen University

Xu Li

Xiamen University

Zhiming Wu ( $\nabla$ zmwu@xmu.edu.cn )

Xiamen University https://orcid.org/0000-0002-9642-6449

Junyong Kang

Xiamen University - Malaysia

\section{Nano Express}

Keywords: Perovskite solar cells, Gradient band structure, Carrier separation efficiency, Carrier recombination loss

Posted Date: May 1st, 2020 
DOI: https://doi.org/10.21203/rs.3.rs-16875/v2

License: (c) (1) This work is licensed under a Creative Commons Attribution 4.0 International License. Read Full License

Version of Record: A version of this preprint was published at Nanoscale Research Letters on June 9th, 2020. See the published version at https://doi.org/10.1186/s11671-020-03359-0. 


\section{Gradient engineered light absorption layer for enhanced carrier separation efficiency in perovskite solar cells}

Gaozhu Wu

Email: 19820171152827@stu.xmu.edu.cn

Qing Zhu

Email: 850745524@qq.com

Teng Zhang

Email:614432080@qq.com

Ziqi Zou

Email: 838281971@qq.com

Weiping Wang

*Corresponding author

Email: wpwang@xmu.edu.cn

Yiyan Cao

Email: xmcyy@xmu.edu.cn

Lijing Kong

Email: lijing-k@xmu.edu.cn

Xuanli Zheng

Email: xlzheng1130@xmu.edu.cn

Yaping $\mathrm{Wu}$

Email: ypwu@xmu.edu.cn

$\mathrm{Xu} \mathrm{Li}$

Email: xuliphys@xmu.edu.cn

Zhiming $\mathrm{Wu}^{*}$

*Corresponding author

Email: zmwu@xmu.edu.cn

Junyong Kang

Email: jykang@xmu.edu.cn

Department of Physics

Fujian Key Laboratory of Semiconductor Materials and Applications, Collaborative 
Innovation Center for Optoelectronic Semiconductors and Efficient Devices Xiamen University

Xiamen 361005, P. R. China 


\begin{abstract}
Carrier transport behavior in perovskite light absorption layer significantly impacts the performance of perovskite solar cells (PSCs). In this work, reduced carrier recombination losses were achieved by the design of band structure in perovskite materials. An ultrathin $\left(\mathrm{PbI}_{2} / \mathrm{PbBr}_{2}\right)_{\mathrm{n}}$ film with a gradient thickness ratio was deposited as the lead halide precursor layer by thermal evaporation method, and PSCs with a gradient band structure in perovskite absorption layer were fabricated by a two-step method in ambient atmosphere. For comparison, PSCs with homogeneous perovskite materials of $\mathrm{MAPbI}_{3}$ and $\mathrm{MAPbI}_{\mathbf{x}} \mathrm{Br}_{3-\mathrm{x}}$ were fabricated as well. It is found that the gradient type-II band structure greatly reduces the carrier lifetime and enhances the carrier separation efficiency. As a result, the PSCs with a gradient band structure exhibit an average power conversion efficiency of $17.5 \%$, which is $1-2 \%$ higher than that of traditional PSCs. This work provides a novel method for developing high-efficient PSCs.
\end{abstract}

\title{
Keywords
}

Perovskite solar cells; Gradient band structure; Carrier separation efficiency; Carrier recombination loss; 


\section{Introduction}

In the last ten years, perovskite solar cells (PSCs) have become the focus of attention in the field of energy because of their high efficiency and low cost [1-6]. Many efforts have been focused on the improvement of cell performance or power conversion efficiency (PCE) [7-13]. As we know, the cell performance essentially depends on incident photon-to-electron conversion efficiency (IPCE) and light absorption efficiency, whereas efficient carrier separation efficiency is the key to improve IPCE. Therefore, it becomes crucial to control the transport of photon-generated carriers in perovskite materials. In traditional planar structure PSCs, carriers (or electron-hole pairs) are separated at the interface between electron transfer layer (ETL) and perovskite material, and only carriers diffusing to the separation interface can have an effect on cell performance. Hence, much work has been devoted to reduce carrier recombination during its diffusion. Different methods, such as solvent annealing [1417], additive engineering [18-20], surface passivation [21-24], etc. have been employed to improve perovskite crystal quality. Actually, band alignment control is an alternative method to reduce recombination losses [25-27]. For example, Jing Zhang et al. introduced extrinsic movable ions $\mathrm{Li}^{+} / \mathrm{I}^{-}$in $\mathrm{MAPbI}_{3}$, and the aggregation of $\mathrm{Li}^{+} / \mathrm{I}^{-}$tuned the energy level of the perovskite, which made charge extraction quite efficient from perovskite materials to both ETL and hole transport layer (HTL) in PSCs [28]. Interestingly, the band structure of organometal halide perovskite materials can be easily adjusted by changing the component or content of halogen element in perovskite materials [29-32]. For instance, Zhang et al. fabricated $\mathrm{MAPbI}_{3} / \mathrm{MAPbI}_{\mathrm{x}} \mathrm{Br}_{3-\mathrm{x}}$ 
heterostructure with a type-II band structure and achieved HTL-free PSCs [33]. In essence, it is an ideal approach to directly reduce recombination losses through the design of a gradient band structure in perovskite light absorption layer [34-35], which supports the carrier separation as fast as possible. However, to the best of our knowledge, it has not been reported so far about the fabrication of perovskite materials with a gradient band structure.

In this work, ultrathin $\mathrm{PbI}_{2}$ and $\mathrm{PbBr} 2$ films were alternately deposited onto the substrate as the lead halide precursor layers by thermal evaporation method, and PSCs with a gradient engineered perovskite absorption layer were fabricated by gradually tuning the thickness ratio of $\mathrm{PbI}_{2}$ to $\mathrm{PbBr}_{2}$ films. For comparison, $\mathrm{PSCs}$ with homogeneous perovskite materials of $\mathrm{MAPbI}_{3}$ and $\mathrm{MAPbI}_{x} \mathrm{Br}_{3-\mathrm{x}}$ were fabricated as well. Scanning electron microscopy (SEM), energy dispersive X-Ray spectroscopy (EDS), X-ray diffraction (XRD), absorption spectra, photoluminescence (PL) spectra, and time-resolved photoluminescence (TRPL) spectra were performed to investigate the morphologies, element distribution, crystal structures, chemical compositions, optical properties, and carrier lifetime of perovskite materials. It is found that the gradient band structure in perovskite light absorption layer significantly reduces the carrier lifetime and enhances the carrier separation efficiency. As a result, the PSCs with a gradient band structure exhibit an average power conversion efficiency of $17.5 \%$, which is $1-2 \%$ higher than that of traditional PSCs. 


\section{Experimental section}

\section{Device fabrication}

Fluorine-doped tin oxide (FTO) glass substrates $(15 \Omega / \mathrm{sq})$ were etched by a laser and cleaned by sequential ultra-sonication in acetone, ethanol, and deionized water for 15 min in each. A compact $\mathrm{SnO}_{2}\left(\mathrm{c}-\mathrm{SnO}_{2}\right)$ layer was deposited on the cleaned FTO substrates by spin-coating $0.1 \mathrm{M}$ tin oxide ethanol solution (Xi'an Polymer) at 3000 $\mathrm{rpm}$ for $30 \mathrm{~s}$, and then annealed at $200{ }^{\circ} \mathrm{C}$ for $120 \mathrm{~min}$. After the substrates were naturally cooled to room temperature, they were immersed in tin tetrachloride solution for $20 \mathrm{~min}$ at $75^{\circ} \mathrm{C}$, and then rinsed with deionized water and dried by nitrogen flow. Three kinds of perovskite layers, i.e. $\mathrm{MAPbI}_{3}, \mathrm{MAPbI}_{\mathrm{x}} \mathrm{Br}_{3-\mathrm{x}}$ and G- $\mathrm{MAPbI}_{\mathrm{x}} \mathrm{Br}_{3-\mathrm{x}}$, were prepared by a two-step method. To fabricate homogeneous $\mathrm{MAPbI}_{3}$ or $\mathrm{MAPbI}_{\mathrm{x}} \mathrm{Br}_{3-\mathrm{x}}$ perovskite films, $\mathrm{PbI}_{2}(99.99 \%$, Xi'an Polymer) with the thickness of $180 \mathrm{~nm}$ was first evaporated on the prepared substrate at a rate of $0.5 \mathrm{~nm} / \mathrm{s}$. To convert lead halides to $\mathrm{MAPbI}_{3}$ materials, the precursor film with a solution of $\mathrm{CH}_{3} \mathrm{NH}_{3} \mathrm{I}$ (MAI) in isopropanol (40 mg/mL) was spin-coated on the substrates. Whereas converting lead halides to MAPbI ${ }_{x} \mathrm{Br}_{3}-\mathrm{x}$, a MAI and $\mathrm{MABr}\left(\mathrm{CH}_{3} \mathrm{NH}_{3} \mathrm{Br}\right)$ mixed isopropanol solution (mole ratio: 4:1) was used as the precursor and spin-coated on the as-prepared $\mathrm{FTO} / \mathrm{c}-\mathrm{SnO}_{2} / \mathrm{PbI}_{2}$ substrates. As for the fabrication of gradient $\mathrm{MAPbI}_{x} \mathrm{Br}_{3-\mathrm{x}}$ perovskite films, $\mathrm{PbI}_{2}$ and $\mathrm{PbBr} 2$ were alternately evaporated onto the $\mathrm{FTO} / \mathrm{c}-\mathrm{SnO}_{2}$ substrate as the lead halide precursor layers, as shown in Fig. 1, by accurately controlling the evaporation time of $\mathrm{PbI}_{2}$ and $\mathrm{PbBr} 2$, and a $180 \mathrm{~nm}$ heterogeneous lead halides layer with a gradient thickness ratio, consisting of $\left(11.6 \mathrm{~nm} \mathrm{PbI}_{2} / 0.4 \mathrm{~nm} \mathrm{PbBr}_{2}\right) /\left(11.2 \mathrm{~nm} \mathrm{PbI}_{2} / 0.8 \mathrm{~nm} \mathrm{PbBr}_{2}\right) / \ldots . . /(6$ 
$\mathrm{nm} \mathrm{PbI}_{2} / 6 \mathrm{~nm} \mathrm{PbBr} 2$ ), was obtained. And then the precursor film with a solution of MAI in isopropanol (40 $\mathrm{mg} / \mathrm{mL})$ was spin-coated on the as-prepared $\mathrm{FTO} / \mathrm{c}$ $\mathrm{SnO}_{2} /\left(\mathrm{PbI}_{2} / \mathrm{PbBr}_{2}\right)_{15}$ substrates. All the above spin-coating speeds were set to $5500 \mathrm{rpm}$, and all the samples were annealed at $110^{\circ} \mathrm{C}$ for $60 \mathrm{~min}$. The hole transport material (HTM) was deposited by spin-coating at $4000 \mathrm{rpm}$ for $30 \mathrm{~s}$, which was composed of 72 mg spiro-OMeTAD, $28.8 \mu \mathrm{L}$ of 4 tert-butylpyridine, and $17.5 \mu \mathrm{L}$ of $520 \mathrm{mg} / \mathrm{mL}$ lithium bis-(triflouromethanesulfonyl) imide in acetonitrile in $1 \mathrm{~mL}$ of chlorobenzene. All the above processes are operated in air atmosphere with a relative humidity of $35 \%$. Finally, $80 \mathrm{~nm}$ thick gold electrodes were deposited on the top of the devices by a thermal evaporation method. The active area of the cell was measured to be $0.07 \mathrm{~cm}^{2}$.

\section{Characterization}

Morphologies of the samples and EDS mapping images were examined by a highresolution field emission SEM (FE-SEM, Zeiss Sigma). Crystal structures were analyzed by XRD (Ultima IV, Rigaku, $\mathrm{Cu} \mathrm{K} \alpha: \lambda=0.15406 \mathrm{~nm}$ ). The absorption spectra of perovskite films were characterized by an UV/Vis spectrophotometer (PerkinElmer, Lambda 850). The current density-voltage (J-V) curves were measured by a digital source meter (B2901A, Keysight) under an AM 1.5 solar simulator (SS150, Zolix). The IPCE was measured in AC mode on a (QE-R, Spectral Response Measurement System) testing system (Enli Technology Co. Ltd.) with a tungsten-halogen lamp as the light source. PL and TRPL spectra were measured by steady-state transient near infrared fluorescence spectrometer (FLS 980) at the laser wavelength of $377 \mathrm{~nm}$ as an excitation source. 


\section{Results and discussion}

The surface and cross-section morphologies of the perovskite films were characterized by SEM. Figures 2(a-c) show the surface images of the perovskite samples of $\mathrm{MAPbI}_{3}$, $\mathrm{MAPbI}_{\mathrm{x}} \mathrm{Br}_{3-\mathrm{x}}$ and gradient $\mathrm{MAPbI} \mathrm{xBr}_{3-\mathrm{x}}$ (labeled as $\mathrm{G}-\mathrm{MAPbI} \mathrm{IBr}_{3}-\mathrm{x}$ ), respectively. The inserts are their cross-sectional images. All the samples exhibit a uniform and compact surface, indicating the good crystal quality of perovskite materials. Notably, the samples demonstrate the different grain sizes. The $\mathrm{MAPbI}_{\mathrm{x}} \mathrm{Br}$-x sample has the average grain size on the order of micrometer, whereas for the $\mathrm{MAPbI}_{3}$ and $\mathrm{G}-\mathrm{MAPbI}_{\mathrm{x}} \mathrm{Br}_{3-\mathrm{x}}$ samples, the grain sizes are $\sim 350 \mathrm{~nm}$ and $\sim 450 \mathrm{~nm}$, respectively. The size difference should be related to the material growth process. As for the $\mathrm{MAPbI}_{\mathrm{x}} \mathrm{Br}_{3-\mathrm{x}}$ sample, a MAI and $\mathrm{MABr}$ mixed isopropanol solution was used as the precursor, whereas, for the other two samples, only the MAI isopropanol solution was adopted. Br atoms in the precursor solution tend to slowly displace I atoms during the growth process because of their different atomic radius, which is conducive to reduce the growth rate and increase the grain size. This behavior is also observed in other reports [36-37]. In addition, as shown in the inserts of Fig. 2, the thickness for all the three samples is controlled to $\sim 350 \mathrm{~nm}$, which is similar to the optimized value in previous report [38].

To elucidate the crystal structures and compositions of different samples, XRD measurements were performed with the results in Fig. 3(a). The diffraction peaks at around $14.1^{\circ}, 28.4^{\circ}, 31.8^{\circ}$, and $40.9^{\circ}$ are indexed to (110), (220), (312), and (330) planes of $\mathrm{MAPbI} 3$ material, respectively. There is no characteristic peak corresponding to hexagonal $\mathrm{PbI}_{2}$ or $\mathrm{PbBr}_{2}$, revealing the complete conversion. With respect to the 
$\mathrm{MAPbI}_{3}$ sample, as shown in the Fig. 3(b), the diffraction peaks of the $\mathrm{MAPbI}_{\mathrm{x}} \mathrm{Br}$-x and $\mathrm{G}-\mathrm{MAPbI}_{\mathrm{x}} \mathrm{Br}_{3-\mathrm{x}}$ samples slightly shift to the larger $2 \theta$ degrees and almost appear at the same position, indicating the analogous doping content of $\mathrm{Br}$ atoms [32]. Figure 3(c) shows their absorption spectra. For the $\mathrm{MAPbI}_{3}$ sample, obvious absorption edge at $\sim 785 \mathrm{~nm}$ is observed, corresponding to a bandgap of $1.58 \mathrm{eV}$. For the other two samples, both the absorption edges move to $\sim 755 \mathrm{~nm}$, corresponding to a bandgap of $1.64 \mathrm{eV}$. Empirically, the bandgap $E_{g}$ can be estimated by the following quadratic equation:

$$
E_{g}\left(M A P b I_{x} B r_{3-x}\right)=2.29-0.35 x+0.037 x^{2},
$$

hence, the $\mathrm{Br}$ content can be estimated to be $\sim 16 \%$ [32]. It is worth noting that although the $\mathrm{MAPbI}_{\mathrm{x}} \mathrm{Br}_{3-\mathrm{x}}$ and $\mathrm{G}-\mathrm{MAPbI}_{\mathrm{x}} \mathrm{Br}_{3-\mathrm{x}}$ samples have almost same absorption edges, their curve slopes exhibit a certain difference. The absorption edge for the G-MAPbI${ }_{x} \mathrm{Br}_{3-\mathrm{x}}$ sample is relatively gentle, which might be because it is a non-homogeneous perovskite material possessing a non-identical bandgap.

The PSCs were fabricated by using the above three samples and labeled as PSC-I, PSC-I/Br, and PSC-G-I/Br, respectively. Figure 4(a) displays the J-V characteristic curves. The detailed performance parameters are summarized in the inserted table. It can be seen that the PSC-G-I/Br exhibits the best performance with a PCE of $18.2 \%$, corresponding to an open-circuit voltage ( $\mathrm{Voc}$ ) of $1.07 \mathrm{~V}$, a short-circuit current density (Jsc) of $22.5 \mathrm{~mA} / \mathrm{cm}^{2}$, and a filling factor (FF) of $75.6 \%$. Understandably, the Voc of both the Br-containing cells is $0.06 \mathrm{~V}$ higher than that of the cell without $\mathrm{Br}$ component, since the Br-doping expands the bandgap of perovskite material and improve the Voc 
[1]. In addition, compared with the other two cells, the PSC-I/Br cell has a significantly reduced Jsc $\left(21.7 \mathrm{~mA} / \mathrm{cm}^{2}\right)$. This might be because of the less light absorption in perovskite material owing to its larger bandgap. To confirm the effectiveness of the experiment, we fabricated 80 devices for each kind of cell. Figure 4(b) exhibits the PCE histograms. Obviously, the PSC-G-I/Br devices have the highest average PCE of $17.5 \%$, whereas the PSC-I and PSC-I/Br devices exhibit the lower average PCEs, corresponding to $\sim 15.8 \%$ and $\sim 16.7 \%$, respectively. Figure $4(\mathrm{c})$ shows the stability results. After three weeks, the cell performance is almost reduced by $60 \%$. Here, it should be mentioned that our experiment is fully operated in air atmosphere (relative humidity: 35\%), and the PSCs with higher efficiency and stability can be hopefully achieved when they are fabricated in a low-humidity environment.

To reveal the mechanism of the improved performance in PSC-G-I/Br devices, the measurements of IPCE, PL, EDS, and TRPL for the different samples were performed. Figure 4(d) shows their IPCE curves with the wavelength range from $300 \mathrm{~nm}$ to 800 $\mathrm{nm}$. There are slight differences in cut-off wavelength and IPCE intensity. As for PSCI device, it shows the largest effective region from $300 \mathrm{~nm}$ to $780 \mathrm{~nm}$, contributing to the maximal Jsc. By contrast, the Br-containing devices (i.e. PSC-I/Br and PSC-G-I/Br) exhibit the shorter cut-off wavelength due to the larger bandgap. Notably, compared with the PSC-I/Br device, the PSC-G-I/Br device has the higher IPCE in the range from $500 \mathrm{~nm}$ to $750 \mathrm{~nm}$, resulting to the larger Jsc. This phenomenon may be related to the light absorption distribution in perovskite material. It is known that the extinction coefficient of perovskite material decreases with the increase of light wavelength in the 
visible range [39]. Therefore, when sunlight is incident on the perovskite cell, the shortwavelength light tends to be absorbed in the region close to the separation interface owing to its small the penetration depth, and the photo-generated carriers have the higher separation efficiency; while the long-wavelength light has the deeper penetration depth, and more photo-generated carriers locate far away from the separation interface, which is not conducive to carrier separation. Accordingly, as shown in Fig. 4(d), for the PSC-I/Br or PSC-I device, the IPCE in the long wavelength is slightly lower than that in the short wavelength. However, for the PSC-G-Br/I device, the gradient energy band structure contributes more to the improvement of the carrier separation efficiency far away from the interface than near the interface. Hence, a significant improvement of IPCE appears in the long wavelength $(500-750 \mathrm{~nm})$.

Figure 5(a) shows their PL spectra measured from the front (from perovskite material) and the back (from the glass). In the case of $\mathrm{MAPbI}_{3}$ and $\mathrm{MAPbI}_{x} \mathrm{Br}_{3-\mathrm{x}}$ materials, the PL peak positions locate at $780 \mathrm{~nm}$ and $752 \mathrm{~nm}$, respectively, corresponding to the bandgap of 1.58 and $1.64 \mathrm{eV}$, which agree well with the results in Fig. 3(c). Meanwhile, the peak positions of PL spectra measured from the different sides are the same, demonstrating the homogenous materials. Interestingly, for the $\mathrm{MAPbI}_{\mathrm{x}} \mathrm{Br}_{3-\mathrm{x}}$, the two PL spectra exhibit the different peak positions locating at $734 \mathrm{~nm}$ and $771 \mathrm{~nm}$, respectively, corresponding to a bandgap difference of $80 \mathrm{meV}$; moreover, the full width at half maximum (FWHM) of PL spectra are broader than that of $\mathrm{MAPbI}_{3}$ or $\mathrm{MAPbI}_{\mathrm{x}} \mathrm{Br}_{3-\mathrm{x}}$ materials. These phenomena should be related to the non-homogeneous $\mathrm{Br}$ distribution in perovskite materials. As for the G-MAPbI $\mathrm{Brr}_{3-\mathrm{x}}$ sample, it is 
equivalent to multi-component material, and the PL spectrum is composed of multiple spectra, resulting in the broadening of FWHM. In addition, when excitation light is incident on different sides, each single spectrum contributes differently to the total PL spectrum. In the case of PL spectrum measured from the front, more contributions are from the surface perovskite material with the larger bandgap, resulting in the peak position of PL spectrum locating at the shorter wavelength. And vice, the peak position of PL spectrum measured from the back locates at the longer wavelength. To further analyze the Br element distribution, EDS mapping of I and Br elements were performed for the $\mathrm{MAPbI}_{x} \mathrm{Br}_{3-\mathrm{x}}$ and G-MAPbI $\mathrm{I}_{\mathrm{x}} \mathrm{Br}_{3-\mathrm{x}}$ samples. As shown in Fig. 5(c-g), the I and $\mathrm{Br}$ elements almost uniformly distribute on the whole perovskite layer for the $\mathrm{MAPbI}_{\mathrm{x}} \mathrm{Br}_{3}$ $\mathrm{x}$ sample; whereas a gradient $\mathrm{I}$ and $\mathrm{Br}$ distribution along the longitudinal direction can be clearly observed for the G-MAPbI ${ }_{x} \mathrm{Br}_{3-\mathrm{x}}$ as shown in Fig. 5(h-1), and moreover, the closer to the FTO substrate, the smaller the Br content. These results are consistent with the original expectation. In addition, it can be seen from Fig. 5(a) that the PL intensity for the G-MAPbI ${ }_{x} \mathrm{Br}_{3-\mathrm{x}}$ material is markedly lower than that for the other two samples. As we know, the emission intensity is significantly impacted by carrier lifetime of perovskite material. Figure 5(b) plots the TRPL spectra measured at $770 \mathrm{~nm}$ for different samples. We fitted the carrier lifetime through a two-component exponential decay function $[40]$ :

$$
F(t)=A+B_{1} \exp \left(\frac{-t}{\tau_{1}}\right)+B_{2} \exp \left(\frac{-t}{\tau_{2}}\right)
$$

where $A$ is the baseline offset constant, $B_{1}$ and $B_{2}$ are the corresponding attenuation amplitudes of this component, and $\tau_{1}$ and $\tau_{2}$ are the decay time. The average 
recombination lifetime $\left(\tau_{\text {ave }}\right)$ can be calculated by the following equation:

$$
\tau_{\text {ave }}=\frac{\sum B_{i} \tau_{i}^{2}}{\sum B_{i} \tau_{i}}
$$

The fitting values of $\tau_{\text {ave }}$ for $\mathrm{MAPbI}_{3}$ and $\mathrm{MAPbI}_{\mathrm{x}} \mathrm{Br}_{3-\mathrm{x}}$ and $\mathrm{G}-\mathrm{MAPbI} \mathrm{Br}_{3-\mathrm{x}}$, are 18.4 ns, $18.1 \mathrm{~ns}$, and $13.1 \mathrm{~ns}$, respectively. It can be seen that the G-MAPbI $\mathrm{BBr}_{3-\mathrm{x}}$ sample has the shortest carrier lifetime. As we know, material quality can also impact the carrier lifetime, and a poor quality will result in a short carrier lifetime [41-43]. According to our XRD results shown in Fig. 3(a), the characteristic peaks at $14.1^{\circ}$ are sharp and their FWHMs are almost same for the three samples, which demonstrate that there is little difference in their crystal qualities $[15,43]$. In addition, no broadening appears for the FWHM of PL spectrum in $\mathrm{MAPbI}_{x} \mathrm{Br}_{3-\mathrm{x}}$ compared with that in $\mathrm{MAPbI}_{3}$, as shown in Fig. 5(a), demonstrating that our fabrication technology is suitable for the preparation of perovskite material with mixed halogen elements. Furthermore, in our experiment, the PSC-G-MAPbI ${ }_{x} \mathrm{Br}_{3-\mathrm{x}}$ exhibits the higher PCE compared with another two kinds of cells, which goes against the poor quality of the G-MAPbI $\mathrm{Brr}_{3-\mathrm{x}}$ material. Hence, it is reasonable to believe that the shorter decay time in TRPL spectrum is mainly attributed to the gradient band structure and the higher carrier separation efficiency in the G$\mathrm{MAPbI}_{\mathrm{x}} \mathrm{Br}_{3-\mathrm{x}}$ material. In this sense, the designed gradient band structure in our experiment is beneficial for the carrier separation and device performance compared with traditional homogeneous band structure.

In order to further elaborate how the gradient band structure affects the performance of PSCs, schematic diagrams of working principle for PSCs with or without a gradient band structure in perovskite material were drawn in Fig. 6. As for 
the traditional structure PSC shown in Fig. 6(a), electron-hole pairs are firstly generated in perovskite materials under light irradiation, and then they are separated at the interface between $\mathrm{SnO}_{2}$ and perovskite material, leading to the current output. From this point of view, only the electron-hole pairs diffusing to the separation interface can contribute to the output current. Hence, improving crystal quality has been extensively employed to enhance cell performance due to the increased number of electron-hole pairs reaching separation interface. Based on previous reports [44], the conductive band for lightly $\mathrm{Br}$-doped perovskite material $\left(\mathrm{MAPbI}_{\mathrm{x}} \mathrm{Br}_{3-\mathrm{x}}\right)$ will gradually increase with the $\mathrm{Br}$ content while the valance band almost keeping fixed. In the light of this, the band structure for the PSC with a gradient $\mathrm{Br}$ content is drawn in Fig. 6(b). Compared with the traditional band structure shown in Fig. 6(a), the gradient structure supports carrier separation inside perovskite materials, which significantly reduces carrier radiative or non-radiative recombination during the diffusion process, thereby improves the carrier separation efficiency and cell performance.

\section{Conclusions}

In this work, perovskite absorption layers with a gradient or non-gradient band structure were designed and fabricated by a two-step method, and three kinds of PSCs, i.e. PSC-I, PSC-I/Br and PSC-G-I/Br, were achieved. The results reveal that the gradient band structure in perovskite absorption layers is beneficial for the reduction of carrier recombination losses. An enhanced carrier separation efficiency and IPCE was achieved in the PSC with a gradient band structure. As a result, the kind of PSCs 
exhibits an average PCE of $17.5 \%$, which is $1-2 \%$ higher than that of traditional PSCs. This work paves a way to design high-efficiency PSCs.

\section{Competing interests}

The authors declare that they have no competing interests.

\section{Acknowledgements}

This work was supported by the National Key Research and Development Program of China (grant no. 2016YFB0400801), the National Natural Science Foundation of China (grant nos., 61774128, 61974123, 61874092, and 61804129), the Natural Science Foundation of Fujian Province of China (grant no 2018I0017), the Fundamental Research Funds for Xiamen Universities, China (20720170085). 


\section{References}

1. Kojima A, Teshima K, Shirai Y, Miyasaka T (2009) Organometal halide perovskites as visible-light sensitizers for photovoltaic cells. J. Am. Chem. Soc. 131(17):6050-6051.

2. Kim H-S, Lee C-R, Im J-H, Lee K-B, Moehl T, Marchioro A, Moon S-J, Humphry-Baker R, Yum J-H, Moser J E et al (2012) Lead iodide perovskite sensitized all-solid-state submicron thin film mesoscopic solar cell with efficiency exceeding 9\%. Scientific Reports 2:591.

3. Zhou H, Chen Q, Li G, Luo S, Song T-b, Duan H-S, Hong Z, You J, Liu Y, Yang Y (2014) Interface engineering of highly efficient perovskite solar cells. Science 345(6196):542-546.

4. Green M A, Bein T (2015) Photovoltaics perovskite cells charge forward. Nature Materials 14(6):559-561.

5. Yang W S, Park B W, Jung E H, Jeon N J, Kim Y C, Lee D U, Shin S S, Seo J, Kim E K, Noh J H et al (2017) Iodide management in formamidinium-lead-halide-based perovskite layers for efficient solar cells. Science 356(6345):1376-1379.

6. Kim M, Kim G H, Lee T K, Choi I W, Choi H W, Jo Y, Yoon Y J, Kim J W, Lee J, Huh D et al (2019) Methylammonium chloride induces intermediate phase stabilization for efficient perovskite solar cells. Joule 3(9):2179-2192.

7. Li B B, Chen Y N, Liang Z Q, Gao D Q, Huang W (2015) Interfacial engineering by using selfassembled monolayer in mesoporous perovskite solar cell. Rsc Advances 5(114):94290-94295.

8. Ma M, Tang Q, Chen H, He B, Yang P (2017) Filling perovskite (5-AVA) $\left(\mathrm{CH}_{3} \mathrm{NH}_{3}\right)_{1-y} \mathrm{PbI}_{3}$ or (5$\mathrm{AVA})_{\mathrm{y}}\left(\mathrm{CH}_{3} \mathrm{NH}_{3}\right)_{1-\mathrm{y}} \mathrm{PbI}_{3-\mathrm{x}} \mathrm{Cl}_{\mathrm{x}}$ halide in a $3 \mathrm{D}$ gel framework for multi-deformable perovskite solar cell. Sol. Energy Mater. Sol. Cells 160:67-76.

9. Jena A K, Kulkarni A, Miyasaka T (2019) Halide perovskite photovoltaics: Background, status, and future prospects. Chem. Rev. 119(5):3036-3103.

10. Jung E H, Jeon N J, Park E Y, Moon C S, Shin T J, Yang T Y, Noh J H, Seo J (2019) Efficient, stable and scalable perovskite solar cells using poly(3-hexylthiophene). Nature 567(7749):511-515.

11. Lin L, Jiang L, Li P, Fan B, Qiu Y (2019) A modeled perovskite solar cell structure with a $\mathrm{Cu}_{2} \mathrm{O}$ hole-transporting layer enabling over $20 \%$ efficiency by low-cost low-temperature processing. J. Phys. Chem. Solids 124:205-211.

12. Zhang P T, Yang F, Kapil G, Ng C H, Ma T L, Hayase S (2019) Preparation of perovskite films under liquid nitrogen atmosphere for high efficiency perovskite solar cells. Acs Sustainable Chemistry \& Engineering 7(4):3956-3961.

13. Baktash A, Amiri O, Saadat M (2020) High efficient perovskite solar cells base on niobium doped $\mathrm{TiO}_{2}$ as a buffer layer. Journal of Nanostructures 10(1):119-127.

14. Jeon N J, Noh J H, Kim Y C, Yang W S, Ryu S, Seok S I (2014) Solvent engineering for highperformance inorganic-organic hybrid perovskite solar cells. Nature Materials 13(9):897-903.

15. Xiao Z G, Dong Q F, Bi C, Shao Y C, Yuan Y B, Huang J S (2014) Solvent annealing of perovskiteinduced crystal growth for photovoltaic-device efficiency enhancement. Adv. Mater. 26(37):65036509.

16. Sun X, Zhang C F, Chang J J, Yang H F, Xi H, Lu G, Chen D Z, Lin Z H, Lu X L, Zhang J C et al (2016) Mixed-solvent-vapor annealing of perovskite for photovoltaic device efficiency enhancement. Nano Energy 28:417-425.

17. Wang Y F, Li S B, Zhang P, Liu D T, Gu X L, Sarvari H, Ye Z B, Wu J, Wang Z M, Chen Z D (2016) Solvent annealing of $\mathrm{PbI}_{2}$ for the high-quality crystallization of perovskite films for solar cells with 
efficiencies exceeding 18\%. Nanoscale 8(47):19654-19661.

18. Zhao W G, Yang D, Liu S F (2017) Organic-inorganic hybrid perovskite with controlled dopant modification and application in photovoltaic device. Small 13(25).

19. Noel N K, Congiu M, Ramadan A J, Fearn S, McMeekin D P, Patel J B, Johnston M B, Wenger B, Snaith H J (2017) Unveiling the influence of ph on the crystallization of hybrid perovskites, delivering low voltage loss photovoltaics. Joule 1(2):328-343.

20. Noel N K, Abate A, Stranks S D, Parrott E S, Burlakov V M, Goriely A, Snaith H J (2014) Enhanced photoluminescence and solar cell performance via lewis base passivation of organic inorganic lead halide perovskites. Acs Nano 8(10):9815-9821.

21. Chen Q, Zhou H P, Song T B, Luo S, Hong Z R, Duan H S, Dou L T, Liu Y S, Yang Y (2014) Controllable self-induced passivation of hybrid lead iodide perovskites toward high performance solar cells. Nano Lett. 14(7):4158-4163.

22. Xin D Y, Tie S J, Yuan R H, Zheng X J, Zhu J G, Zhang W H (2019) Defect passivation in hybrid perovskite solar cells by tailoring the electron density distribution in passivation molecules. Acs Applied Materials \& Interfaces 11(47):44233-44240.

23. Wang F, Geng W, Zhou Y, Fang H H, Tong C J, Loi M A, Liu L M, Zhao N (2016) Phenylalkylamine passivation of organolead halide perovskites enabling high-efficiency and air-stable photovoltaic cells. Adv. Mater. 28(45):9986-9992.

24. Zheng X P, Chen B, Dai J, Fang Y J, Bai Y, Lin Y Z, Wei H T, Zeng X C, Huang J S (2017) Defect passivation in hybrid perovskite solar cells using quaternary ammonium halide anions and cations. Nature Energy 2(7).

25. Filip M R, Eperon G E, Snaith H J, Giustino F (2014) Steric engineering of metal-halide perovskites with tunable optical band gaps. Nature Communications 5:5757.

26. Todorov T, Gershon T, Gunawan O, Lee Y S, Sturdevant C, Chang L Y, Guha S (2015) Monolithic perovskite-cigs tandem solar cells via in situ band gap engineering. Advanced Energy Materials 5(23):1500799.

27. Ye H Y, Liao W Q, Hu C L, Zhang Y, You Y M, Mao J G, Li P F, Xiong R G (2016) Bandgap engineering of lead-halide perovskite-type ferroelectrics. Adv. Mater. 28(13):2579-2586.

28. Zhang J, Chen R J, Wu Y Z, Shang M H, Zeng Z B, Zhang Y, Zhu Y J, Han L Y (2018) Extrinsic Movable Ions in $\mathrm{MAPbI}_{3}$ Modulate Energy Band Alignment in Perovskite Solar Cells. Advanced Energy Materials 8(5):1701981.

29. Cui D, Yang Z D, Yang D, Ren X D, Liu Y C, Wei Q B, Fan H B, Zeng J H, Liu S Z (2016) Colortuned perovskite films prepared for efficient solar cell applications. Journal of Physical Chemistry C 120(1):42-47.

30. Kulkarni S A, Baikie T, Boix P P, Yantara N, Mathews N, Mhaisalkar S (2014) Band-gap tuning of lead halide perovskites using a sequential deposition process. Journal of Materials Chemistry A 2(24):9221-9225.

31. Liu Y C, Yang Z, Cui D, Ren X D, Sun J K, Liu X J, Zhang J R, Wei Q B, Fan H B, Yu F Y et al (2015) Two-inch-sized perovskite $\mathrm{CH}_{3} \mathrm{NH}_{3} \mathrm{PbX}_{3}(\mathrm{X}=\mathrm{Cl}, \mathrm{Br}$, I) Crystals: Growth and characterization. Adv. Mater. 27(35):5176-5183.

32. Noh J H, Im S H, Heo J H, Mandal T N, Seok S I (2013) Chemical management for colorful, efficient, and stable inorganic-organic hybrid nanostructured solar cells. Nano Lett. 13(4):17641769.

33. Zhang S F, Zhang C M, Bi E B, Miao X L, Zeng H B, Han L Y (2017) Organic-inorganic halide 
perovskite solar cell with $\mathrm{CH}_{3} \mathrm{NH}_{3} \mathrm{PbI}_{2} \mathrm{Br}$ as hole conductor. J. Power Sources 339:61-67.

34. Luo Q, Wu Z M, He J L, Cao Y Y, Bhutto W A, Wang W P, Zheng X L, Li S P, Lin S Q, Kong L J et al (2015) Facile synthesis of composition-tuned $\mathrm{ZnO} / \mathrm{Zn}_{\mathrm{x}} \mathrm{Cd}_{1-\mathrm{x}} \mathrm{Se}$ nanowires for photovoltaic applications. Nanoscale Research Letters 10:181.

35. Wang W P, He J L, Cao Y Y, Kong L J, Zheng X L, Wu Y P, Chen X H, Li S P, Wu Z M, Kang J Y (2017) Nonuniform effect of carrier separation efficiency and light absorption in type-ii perovskite nanowire solar cells. Nanoscale Research Letters 12:160.

36. Yang M J, Zhang T Y, Schulz P, Li Z, Li G, Kim D H, Guo N J, Berry J J, Zhu K, Zhao Y X (2016) Facile fabrication of large-grain $\mathrm{CH}_{3} \mathrm{NH}_{3} \mathrm{PbI}_{3-\mathrm{x}} \mathrm{Br}_{\mathrm{x}}$ films for high-efficiency solar cells via $\mathrm{CH}_{3} \mathrm{NH}_{3} \mathrm{Br}$-selective Ostwald ripening. Nature Communications 7:12305.

37. Zhu W, Bao C, Li F, Yu T, Gao H, Yi Y, Yang J, Fu G, Zhou X, Zou Z (2016) A halide exchange engineering for $\mathrm{CH}_{3} \mathrm{NH}_{3} \mathrm{PbI}_{3-\mathrm{x}} \mathrm{Br}_{\mathrm{x}}$ perovskite solar cells with high performance and stability. Nano Energy 19:17-26.

38. Liu D Y, Gangishetty M K, Kelly T L (2014) Effect of $\mathrm{CH}_{3} \mathrm{NH}_{3} \mathrm{PbI}_{3}$ thickness on device efficiency in planar heterojunction perovskite solar cells. Journal of Materials Chemistry A 2(46):1987319881.

39. Jiang Y J, Green M A, Sheng R, Ho-Baillie A (2015) Room temperature optical properties of organic-inorganic lead halide perovskites. Sol. Energy Mater. Sol. Cells 137:253-257.

40. Jin X, Lei X Y, Wu C Y, Jiang G S, Liu W F, Zeng H L, Chen T, Zhu C F (2017) $\mathrm{Cu}_{2-\mathrm{x}} \mathrm{GeS}_{3}$ : A new hole transporting material for stable and efficient perovskite solar cells. Journal of Materials Chemistry A 5(37):19884-19891.

41. Zheng H, Liu D, Wang Y, Yang Y, Li H, Zhang T, Chen H, Ji L, Chen Z, Li S (2020) Synergistic effect of additives on 2D perovskite film towards efficient and stable solar cell. Chem. Eng. J. 389:124266.

42. Zhang X, Ren X D, Liu B, Munir R, Zhu X J, Yang D, Li J B, Liu Y C, Smilgies D M, Li R P et al (2017) Stable high efficiency two-dimensional perovskite solar cells via cesium doping. Energy \& Environmental Science 10(10):2095-2102.

43. Zhang X, Wu G, Fu W, Qin M, Yang W, Yan J, Zhang Z, Lu X, Chen H (2018) Orientation regulation of phenylethylammonium cation based 2D perovskite solar cell with efficiency higher than $11 \%$. 8(14):1702498.

44. Kitazawa N, Watanabe Y, Nakamura Y (2002) Optical properties of $\mathrm{CH}_{3} \mathrm{NH}_{3} \mathrm{PbX}_{3}(\mathrm{X}=$ halogen) and their mixed-halide crystals. Journal of Materials Science 37(17):3585-3587. 


\section{Figure captions}

Figure 1 Schematics of the fabrication process of gradient $\mathrm{MAPbI}_{\mathrm{x}} \mathrm{Br}_{3-\mathrm{x}}$ perovskite films.

Figure 2 The surface and cross-section morphologies of perovskite films, (a) MAPbI , (b) $\mathrm{MAPbI}_{\mathrm{x}} \mathrm{Br}_{3-\mathrm{x}}$, and (c) G-MAPbI $\mathrm{IBr}_{3-\mathrm{x}}$. The inserts are their cross-sectional images.

Figure 3 (a) XRD patterns of perovskite films, (b) their partial enlargement, and (c) absorption spectra.

Figure 4 (a) $J-V$ curves of the PSCs, the insert is their parameter results; (b) The PCE histograms of PSC devices; (c) PCE evolution of unencapsulated devices under dark storage in a dry box $\left(25^{\circ} \mathrm{C}, \mathrm{RH} 30 \%\right)$; (d) IPCE curves of the PSCs.

Figure 5 (a) Steady-state PL spectra; (b) TRPL spectra; (c) Cross-section image of an MAPbI $\mathrm{IBr}_{3-\mathrm{x}}$ film; (d) and (e) EDS mapping images of I and $\mathrm{Br}$ elements in the area marked in (c), respectively; (f) and (g) Relative intensity of I and $\mathrm{Br}$ element based on (d) and (e) images along the longitudinal direction; (h) Cross-section image of an G-MAPbI ${ }_{x} B_{3-x}$ film; (i) and (j) EDS mapping images of I and Br elements in the area marked in (h), respectively; (k) and (l) Relative intensity of I and Br element based on (i) and (j) images along the longitudinal direction.

Figure 6 Schematic diagrams of working principle for different PSCs, (a) PSC without a gradient type-II band structure; (b) PSC with a gradient band structure. 


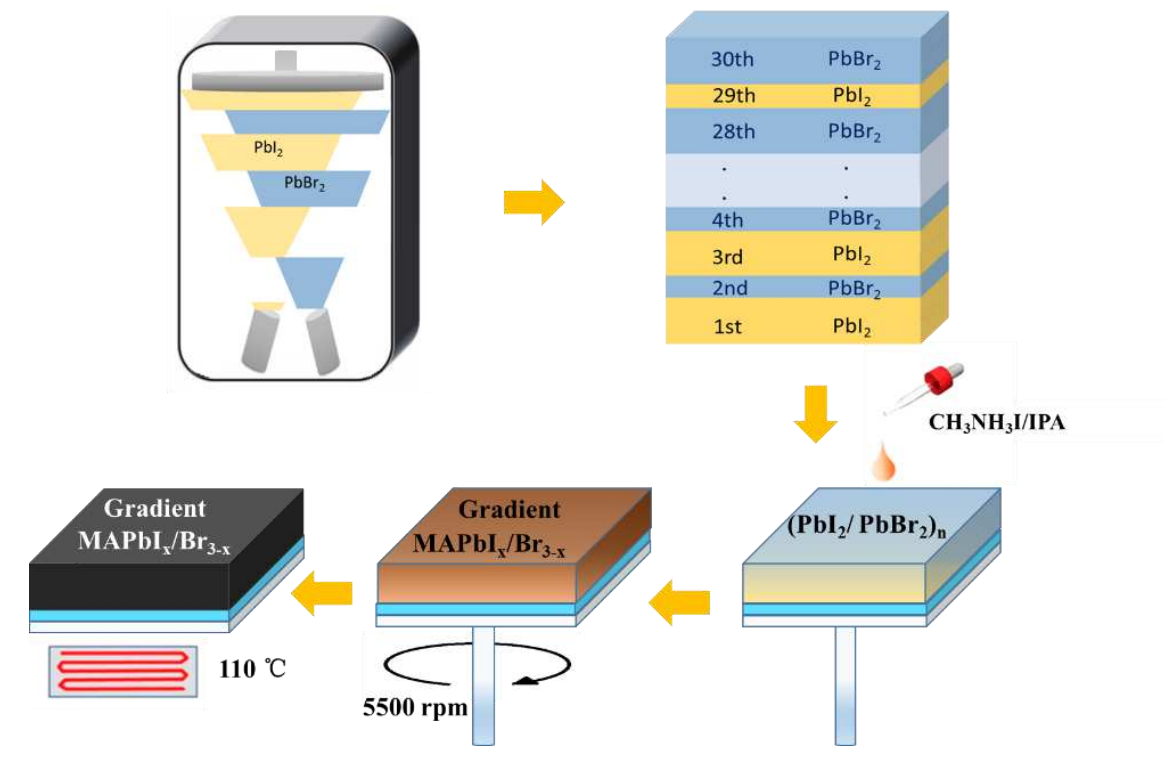

Figure 1 

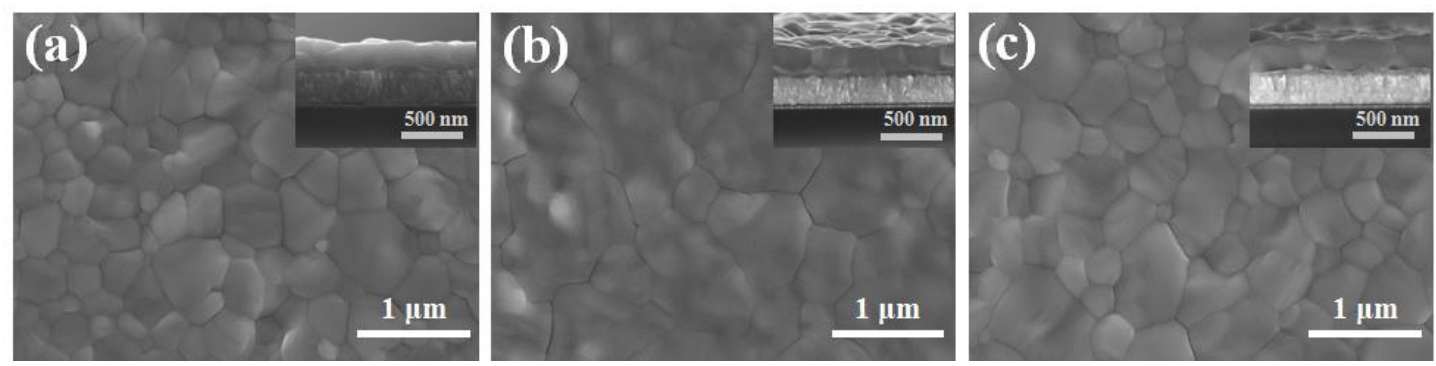

Figure 2 

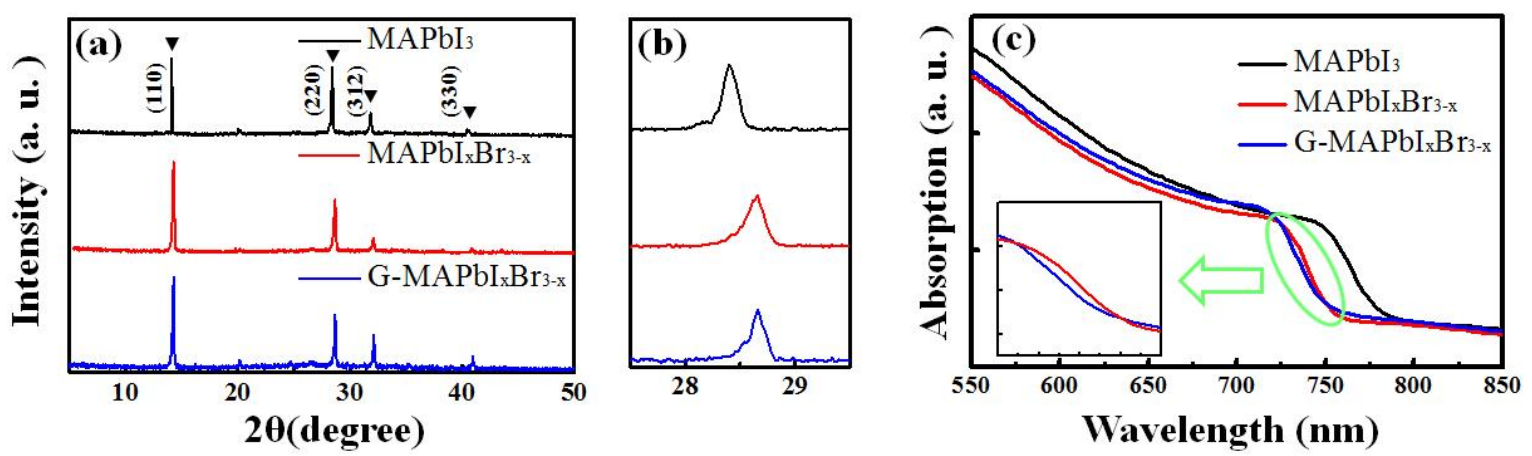

Figure 3 

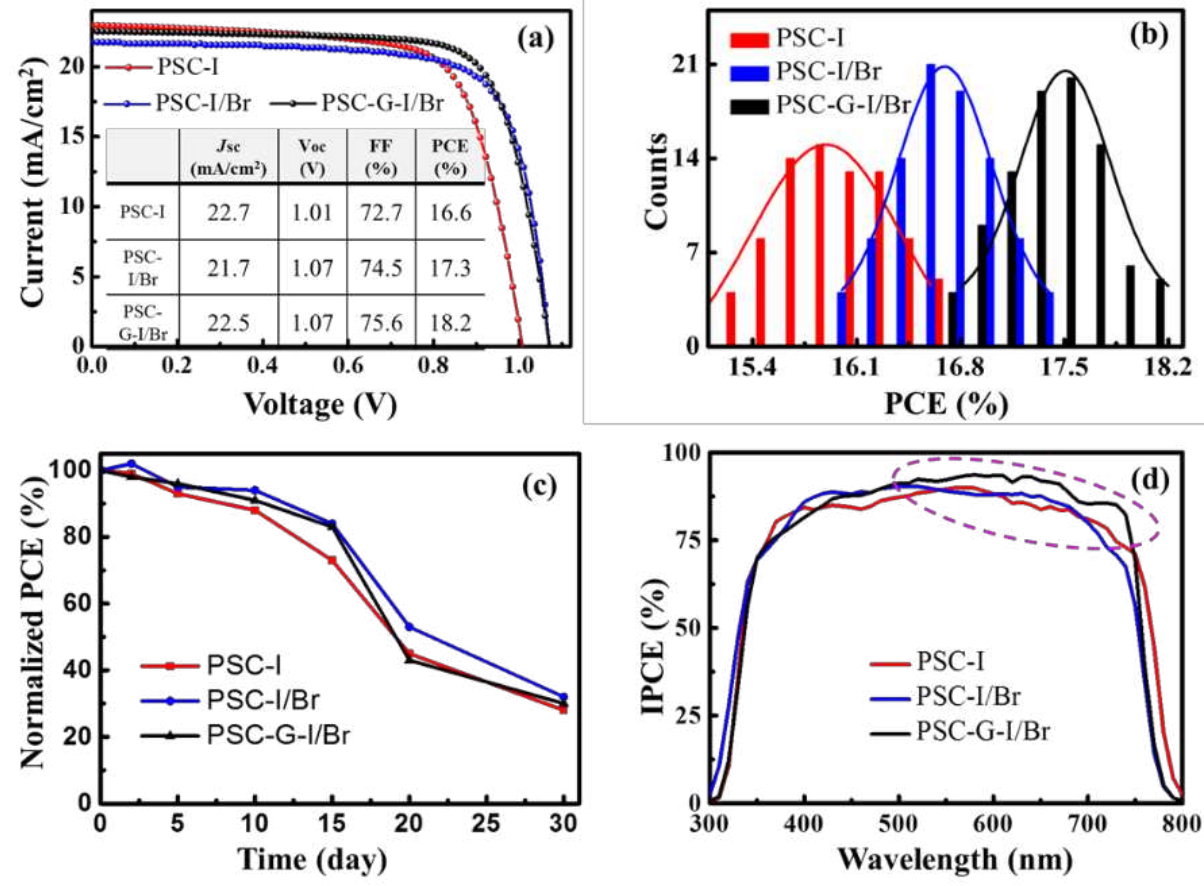

Figure 4 

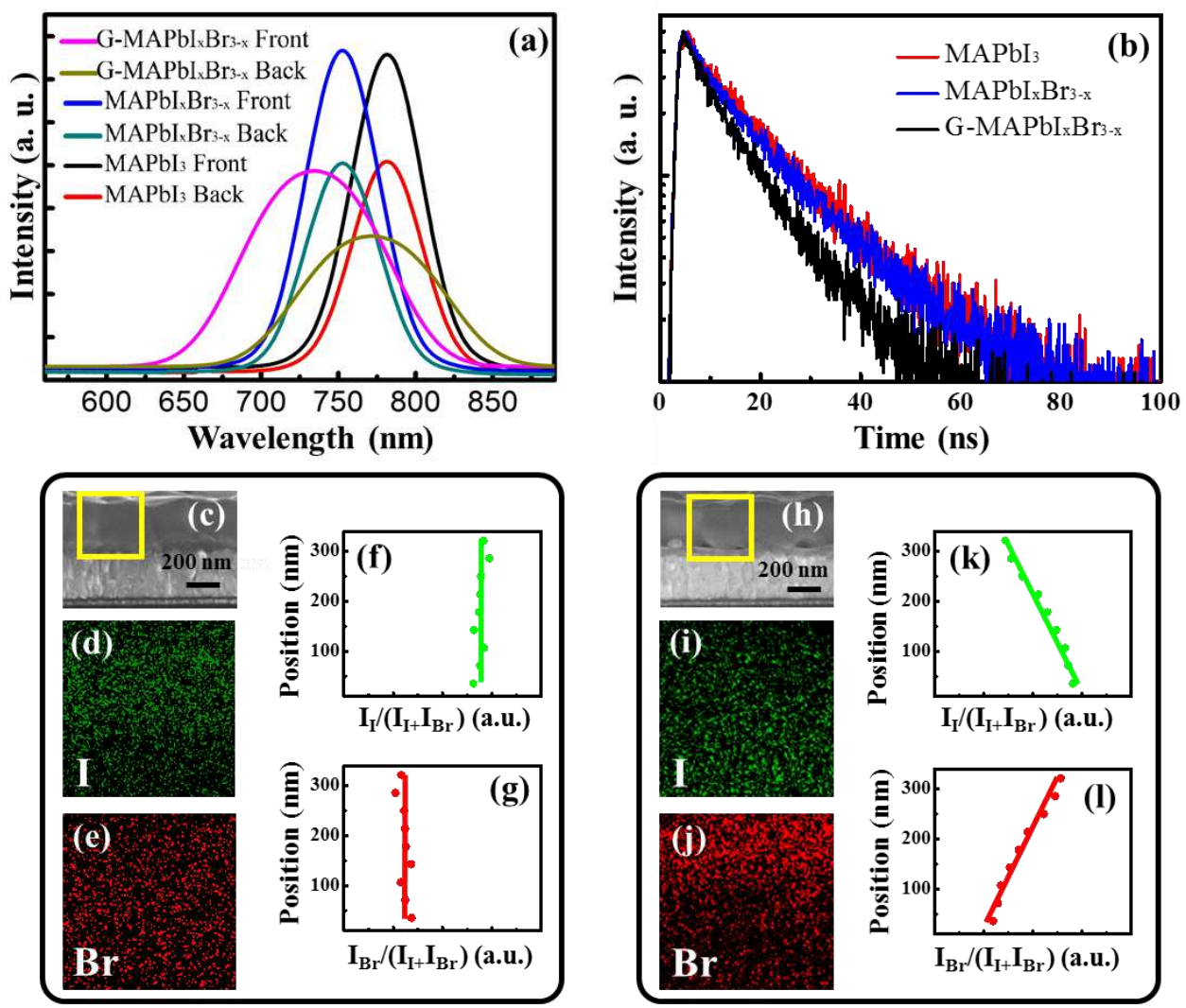

Figure 5 


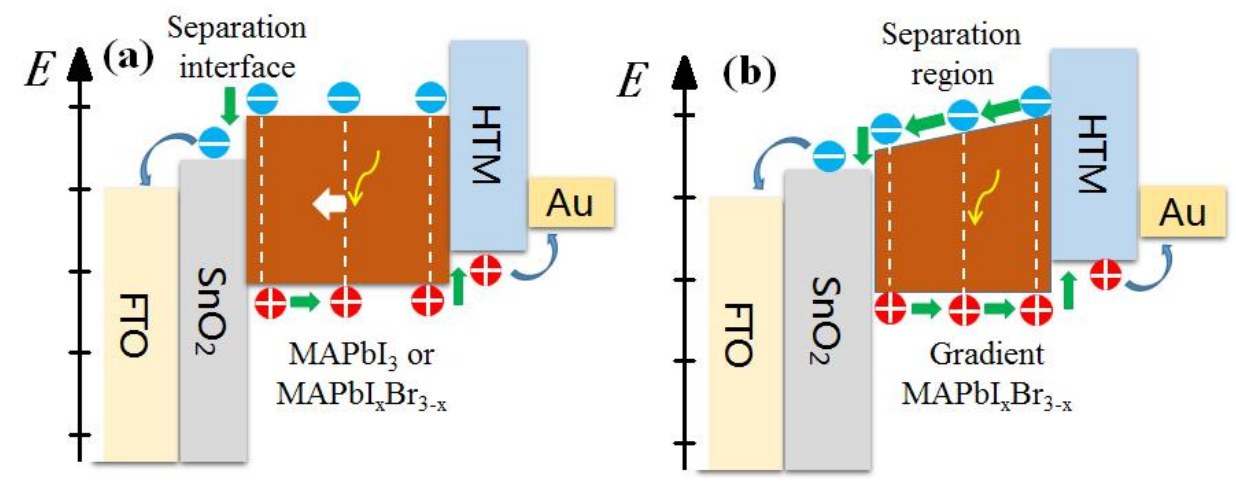

Figure 6 

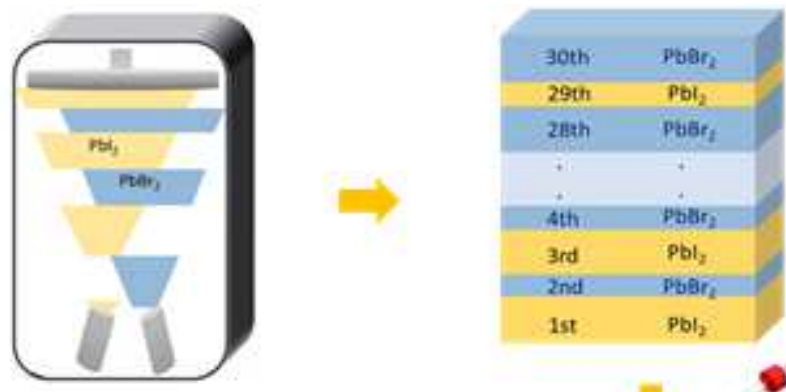

\section{$\mathrm{CH}_{3} \mathrm{NH}_{3} \mathrm{~L} / \mathrm{PA}$}

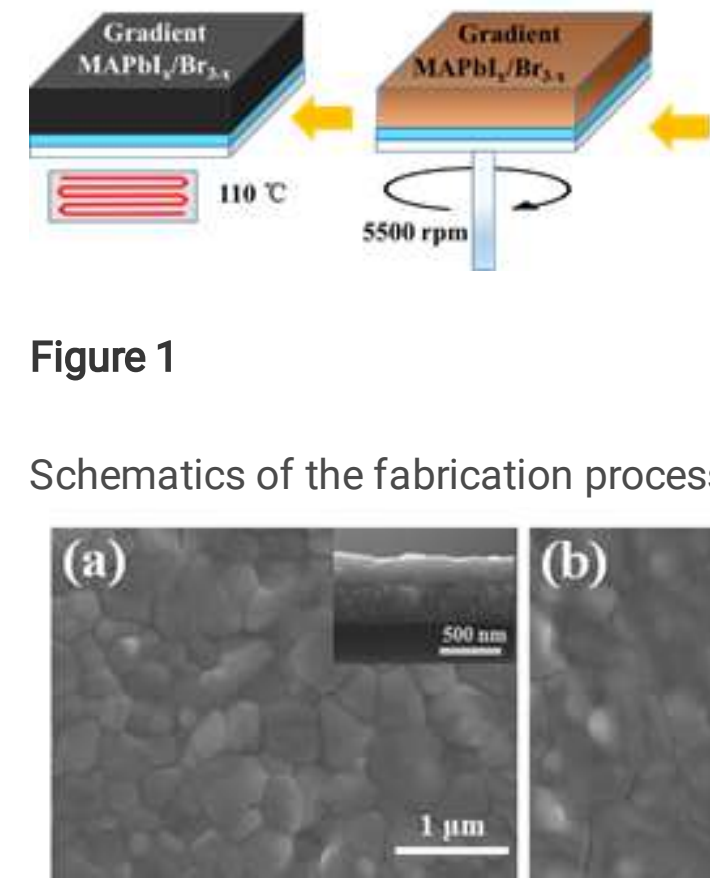

Gradient

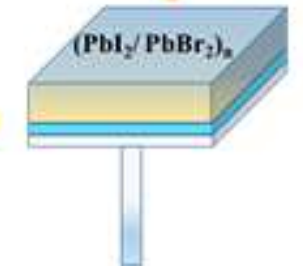

\section{Figure 1}

Schematics of the fabrication process of gradient MAPblxBr3-x perovskite films.
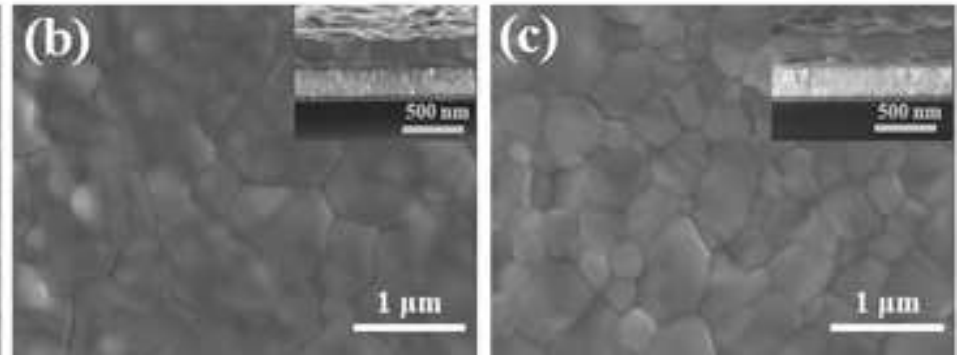

Figure 2

The surface and cross-section morphologies of perovskite films, (a) MAPbI3, (b) MAPblxBr3-x, and (c) GMAPbIxBr3-x. The inserts are their cross-sectional images.
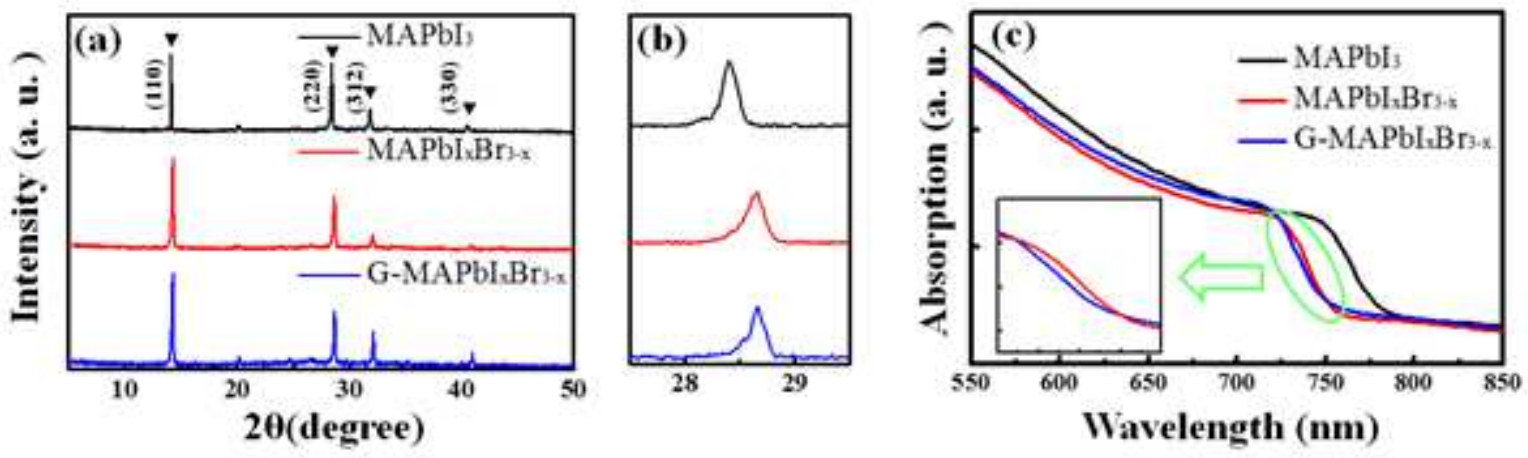

Figure 3 
a) XRD patterns of perovskite films, (b) their partial enlargement, and (c) absorption spectra.
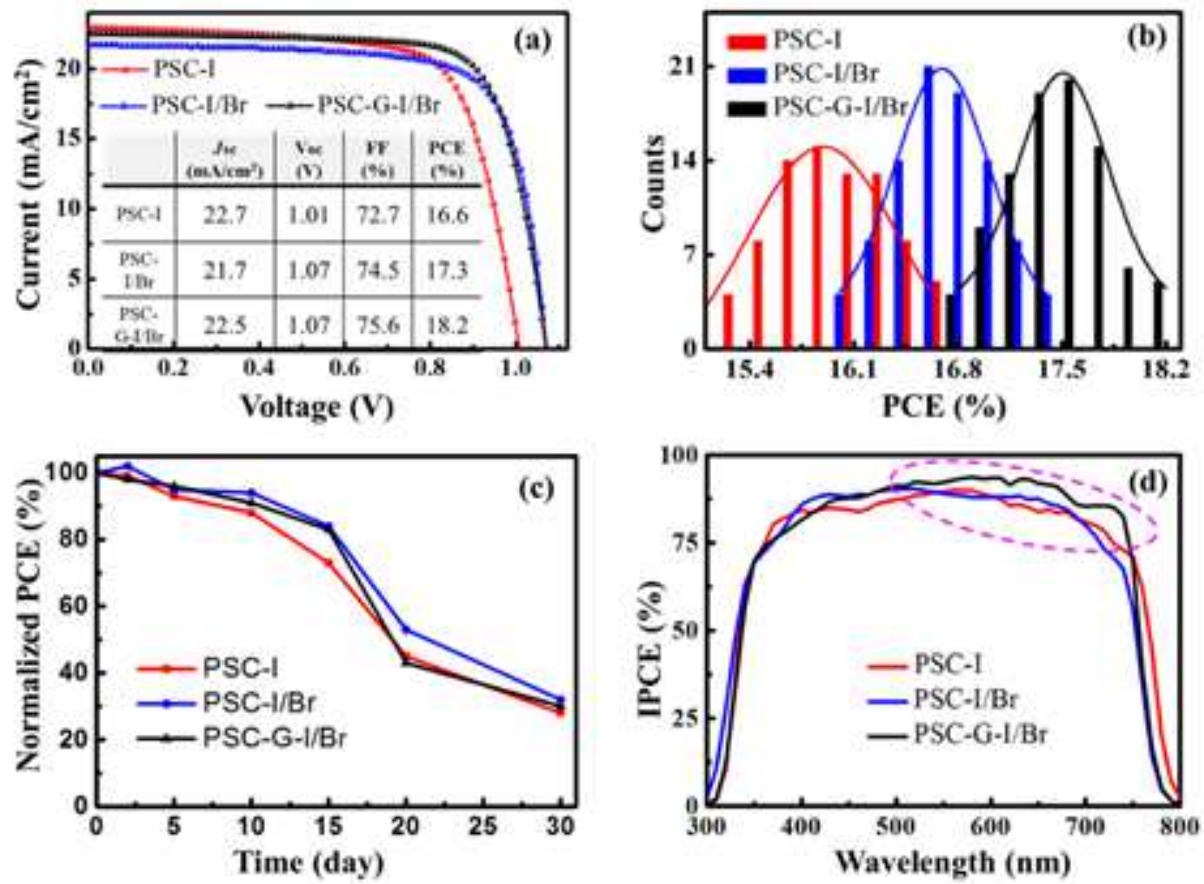

Figure 4

(a) J-V curves of the PSCs, the insert is their parameter results; (b) The PCE histograms of PSC devices;

(c) PCE evolution of unencapsulated devices under dark storage in a dry box $\left(25^{\circ} \mathrm{C}, \mathrm{RH} 30 \%\right)$; (d) IPCE curves of the PSCs.
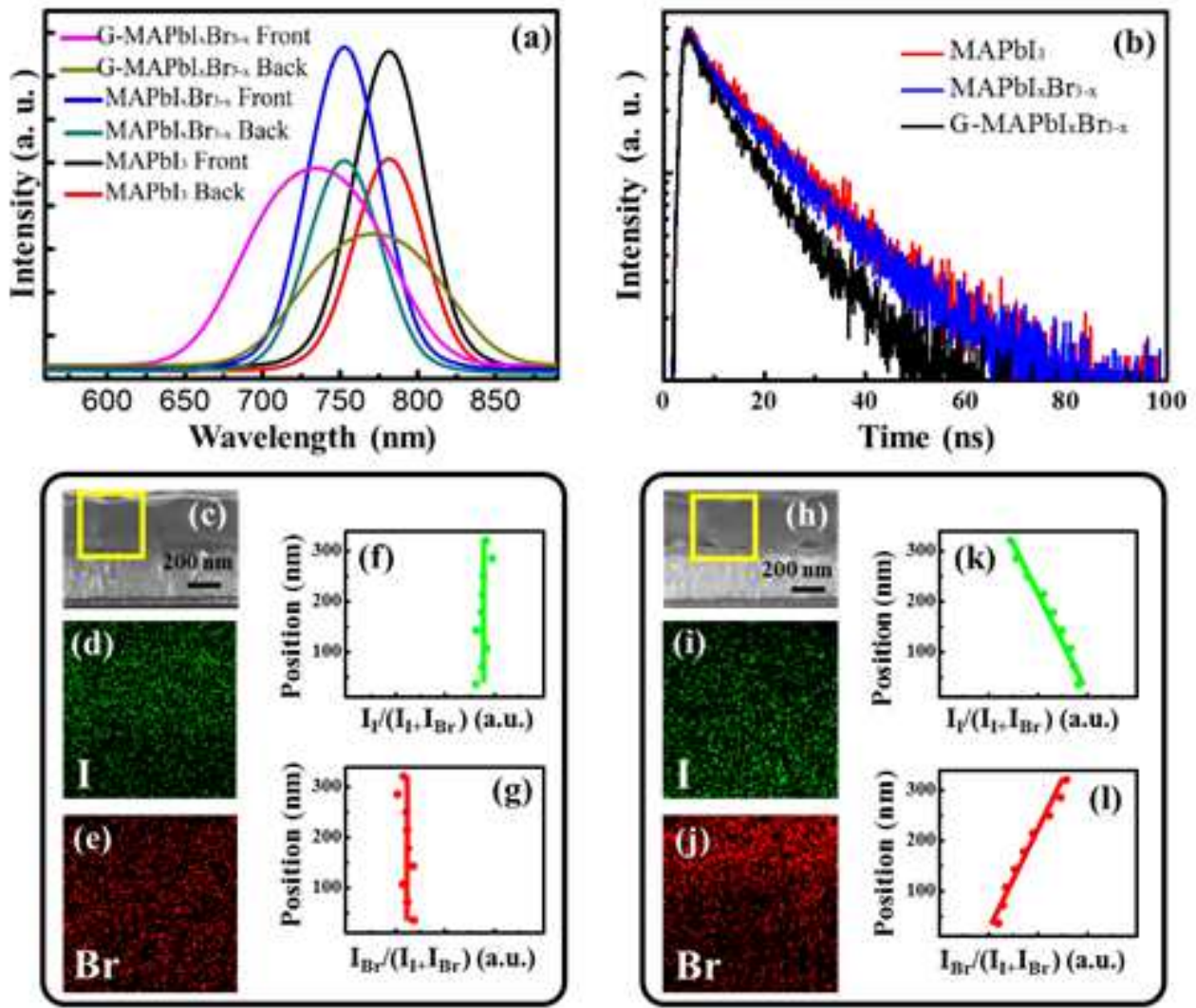
Figure 5

(a) Steady-state PL spectra; (b) TRPL spectra; (c) Cross-section image of an MAPblxBr3-x film; (d) and (e) EDS mapping images of I and Br elements in the area marked in (c), respectively; ( $f$ ) and (g) Relative intensity of I and Br element based on (d) and (e) images along the longitudinal direction; (h) Crosssection image of an G-MAPbIxBr3-x film; (i) and (j) EDS mapping images of I and Br elements in the area marked in (h), respectively; ( $k$ ) and (I) Relative intensity of I and Br element based on (i) and (j) images along the longitudinal direction.
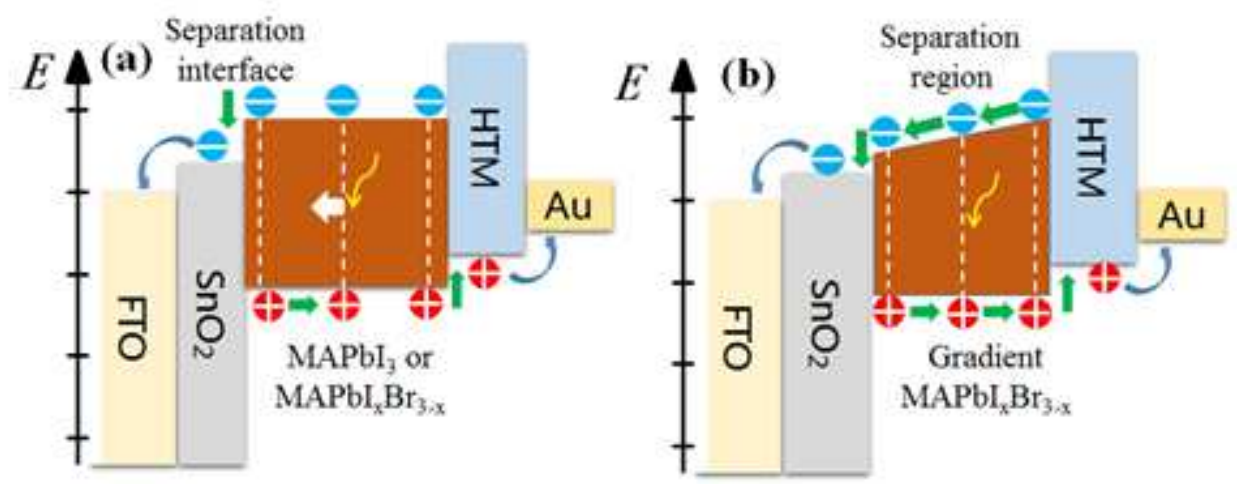

Figure 6

Schematic diagrams of working principle for different PSCs, (a) PSC without a gradient type-Il band structure; (b) PSC with a gradient band structure. 